\title{
INCLUSÃO DAS TDIC DURANTE A PANDEMIA E A FORMAÇÃO CONTINUADA DE PROFESSORES DAS SALAS DE RECURSOS MULTIFUNCIONAIS
}

\author{
Sonia de Fátima Cristina Scheitel dos Passos ${ }^{1}$ \\ Vanessa Bernardi ${ }^{2}$ \\ Elenice Parise Foltran ${ }^{3}$ \\ Rita de Cássia da Silva Oliveira ${ }^{4}$
}

\section{RESUMO}

Este artigo busca refletir sobre as mudanças que ocorreram no cotidiano escolar, a partir da inserção das tecnologias digitais de informação e comunicação - TDIC, por meio da implementação do ensino remoto emergencial - ERE, no período de pandemia, ocasionada pelo COVID-19, nas salas de recursos multifuncionais - SRM. Em especial, este trabalho tenta vislumbrar sobre a formação continuada dos professores para $\mathrm{o}$ atendimento dessa nova demanda, no que tange o uso das TDIC para um público específico. A questão norteadora deste trabalho foi: os professores receberam formação continuada suficiente para inserir as TDIC nas SRM durante a pandemia? A pesquisa assentou-se teoricamente em autores que discutem sobre as TDIC no ensino, desses destacam-se: Moran (2005), Masetto (2000), Valente (2005) entre outros e autores que discutem sobre a Educação Inclusiva e a inserção das TDIC como: Cortelazzo (2012), Loureiro et al (2020), Viana et al. (2019) e Silva Neto et al (2018). Foi elaborado como instrumento de coleta de dados, um questionário do Google Forms, o qual foi respondido por 17 educadores, atuantes nas salas de recursos multifuncionais da rede pública do Estado do Paraná. Como resultado, percebeu-se que os docentes se esforçaram para dar conta do ensino no período de pandemia, que novas dificuldades surgiram, principalmente em relação à sua formação continuada e ao manuseio das TDIC de forma efetiva. Por isso, o estudo apontou que o trabalho pós-pandemia carece de maior atenção tanto no atendimento dos alunos das SRM como da formação continuada do professor.

Palavras-chave: Pandemia de COVID-19. Formação Continuada. Salas de Recursos Multifuncionais.

\footnotetext{
${ }^{1}$ Mestrado do Programa de Pós-Graduação em Educação Inclusiva pela Universidade Estatual do Paraná PROFEI. E-mail: crystinapassos@gmail.com.

${ }^{2}$ Mestrado do Programa de Pós-Graduação em Educação Inclusiva pela Universidade Estatual do Paraná PROFEI. E-mail: nessabernardi@gmail.com.

${ }^{3}$ Doutorado em Educação pela Universidade Estadual de Ponta Grossa. E-mail: epfoltran@uepg.br

${ }^{4}$ Pós-doutorado em Filosofia e Ciências da Educação pela Universidade de Santiago de Compostela. E-mail: soliveira@uepg.br
} 


\title{
THE INCLUSION OF TDICS IN THE PANDEMIC AND THE CONTINUING TRAINING OF TEACHERS IN THE MULTIFUNCTIONAL RESOURCES ROOMS
}

\begin{abstract}
This article reflects on the changes that have occurred in daily school life, since the adoption of information and communication technologies (ICTs), through the implementation of emergency remote teaching, during the COVID-19 pandemic period, in multifunctional resource rooms (MRR). This work focuses on the continuing teacher's education to meet this new demand, regarding the use of ICT for this specific audience. The guiding question for this work was: did teachers receive sufficient continuing education to introduce ICT in MRR during the pandemic?" The research was based theoretically on authors who discuss ICT in teaching, such as Moran (2005), Masetto (2000), Valente (2005) among others, and on authors who discuss Inclusive Education and the insertion of ICT, such as: Cortelazzo (2012), Loureiro et al (2020), Viana et al. (2019), and Silva Neto et al (2018). To collect the data, it was developed and distributed a questionnaire through Google Forms, which has been answered by seventeen multifunctional resource rooms educators, from Paraná State public school system. As result, it was noticeable the teachers' efforts to cope with teaching during the pandemic period, and the arrival of new difficulties, especially in relation to their continuing education and the effectiveness of ICT usage. Therefore, the study pointed out that the post-pandemic work needs more attention, both in the care of MRR students and in the teachers' continuing education.
\end{abstract}

Keywords: COVID-19 pandemic. Continuing Education. Multifunctional Resource Rooms.

\section{LA INCLUSIÓN DEL TDICS EN LA PANDEMIA Y LA FORMACIÓN CONTINUA DE LOS PROFESORES DE LAS SALAS DE RECURSOS MULTIFUNCIONALES}

\section{RESUMEN}

Este artículo busca reflejar sobre los cambios que se han producido en la vida escolar diaria, desde la inserción de las tecnologías digitales de la información y la comunicación - TDIC, a través de la implementación de la educación a distancia de emergencia -EDE, durante el período de pandemia, causado por el COVID-19, en las aulas de recursos multifuncionales - MRS. En particular, se trata de vislumbrar la formación continua de los docentes para atender esta nueva demanda en cuanto al uso de TDIC para un público específico. La 
cuestión de este trabajo fue: ¿Recibieron los maestros suficiente educación continua para incluir TDIC en el SRM durante la pandemia? La investigación se basó teóricamente en autores que discuten el TDIC en la docencia como: Moran (2005), Masetto (2000), Valente (2005) entre otros y autores que discuten la Educación Integrada y la inserción del TDIC como: Cortelazzo (2012), Loureiro et al (2020), Viana et al. (2019) y Silva Neto et al (2018). Para la elaboración de este estudio, se desarrolló un cuestionario de Google Forms como instrumento de recolección de datos, el cual fue respondido por 17 educadores, trabajando en salas de recursos multifuncionales en la red pública del Estado de Paraná. Como resultado, se notó que los profesores se esforzaron por afrontar la docencia durante el período pandémico, que surgieron nuevas dificultades, especialmente en relación con su formación continua y el manejo efectivo del TDIC. Por lo tanto, el estudio señaló que el trabajo pospandémico necesita más atención tanto en el cuidado de los estudiantes de MRS como en la formación continua del docente.

Palabras-clave: Pandemia de COVID-19. Educación continua. Salas de Recursos Multifuncionales.

\section{INTRODUÇÃO}

Atualmente, a sociedade está movimentada pela tecnologia, a cada dia novos recursos tecnológicos emergem, despertando novas necessidades e interesses. Essa realidade afeta também a escola em dois sentidos: no seu público, que já nasceu imerso nas tecnologias, ou seja, são nativos digitais e no sentido de que professores que são imigrantes digitais necessitam de formação continuada para atender essa nova demanda. (PRENSKY, 2001).

Além disso, a pandemia gerada pelo Covid-19 em 2020 trouxe mudanças significativas em relação ao uso da tecnologia, conforme destacam Martiniak, Foltran e Oliveira (2020, p. 41):

Apesar de vivermos cercados pela TIDC, quando a Organização Mundial da Saúde (OMS) indicou algumas medidas para combater a Covid-19, em março de 2020, entre elas o isolamento social e consequentemente a suspensão das aulas, houve enorme preocupação das entidades educacionais em desenvolver planos para a continuidade dos estudos por meios alternativos, haja visto que nenhum sistema de ensino estava preparado para atender a esse desafio. Foi neste contexto que a tecnologia despontou como recurso para manter a educação escolar em andamento.

Esse cenário suscita discussões acerca do uso das tecnologias nas escolas, especificamente para o Atendimento Educacional Especializado (AEE), que segundo Cabral e Bottentuit Junior (2016, p. 1): 
Um serviço da educação especial que se caracteriza como uma proposta de apoio aos alunos, no sentido de ofertar práticas pedagógicas estratégicas e recursos que favoreçam o desenvolvimento integral dos mesmos e a efetivação do seu processo de escolarização.

Esse apoio deve estar articulado com a proposta da escola regular, no entanto, devem diferenciar-se daquelas realizadas na sala de aula comum e devem ser realizadas prioritariamente, nas salas de recursos da própria escola ou de outra escola regular.

As Salas de Recursos Multifuncionais (SRM) foram idealizadas a partir do Programa de Implantação das Salas de Recursos Multifuncionais, como espaço organizado com material didático, recursos pedagógicos, tecnológicos, de acessibilidade e de natureza pedagógica, objetivando a oferta do Atendimento Educacional Especializado (AEE) na rede regular de ensino para o público da educação especial. (BRASIL, 2007).

Se para a educação, de modo geral, a inclusão da TDIC já se configurava como um desafio durante a pandemia, para a educação especial e para os professores que atuam nas SRM, as dificuldades de incluir as tecnologias digitais no seu trabalho docente foram maiores.

Considerando a necessidade de refletir sobre a atuação dos docentes neste contexto e sobre a formação necessária para atender as demandas impostas pela atual conjuntura, levanta-se a seguinte questão de pesquisa: os professores receberam formação continuada suficiente para inserir as TDIC nas SRM durante a pandemia?

Para conduzir essa discussão, o presente artigo está organizado em três seções. Na primeira, "As TDIC na Educação e nas Salas de Recursos Multifuncionais" aborda-se a importância das tecnologias para a Educação e para as SRM. Na segunda, destaca-se a importância da formação continuada docente para o uso das TDIC. Já na terceira seção, descrevem-se os procedimentos metodológicos adotados na pesquisa. Em seguida, apresenta-se a discussão dos resultados e, por fim, as considerações advindas dos resultados do estudo.

\section{As TDIC NA EDUCAÇÃO E NAS SALAS DE RECURSOS MULTIFUNCIONAIS}

Verifica-se cada vez mais que as TDIC ganham espaço na escola, dispondo de diversos recursos, com diferentes finalidades, colocando os educandos diante de novas possibilidades de acesso à informação, contribuindo para o aprimoramento do processo de ensino-aprendizagem. Essa incorporação de tecnologias com os conteúdos básicos do ensino é um elemento que pode contribuir para uma aprendizagem significativa e inclusiva. Frente a esta situação, as instituições educacionais enfrentam o desafio não apenas de incorporar as novas tecnologias como conteúdo do ensino, mas promover e desenvolver práticas pedagógicas que gerem o desenvolvimento de uma atitude reflexiva frente aos conhecimentos e o seu uso tecnológico. 
Masetto (2000) descreve a existência de duas denominações de técnicas para a mediação pedagógica de qualidade, capazes de promover práticas diferenciadas. A primeira está relacionada às técnicas denominadas "tradicionais" ou "convencionais", já utilizadas há algum tempo e que são muito importantes para a aprendizagem em processo presencial. E a segunda se relaciona com as denominadas novas tecnologias, "aquelas que estão vinculadas ao uso do computador, à informática, à telemática e à educação a distância." (MASETTO, 2000. p.147). O autor ainda destaca que os professores não utilizam das tecnologias, ou por não as conhecerem, ou por não dominarem sua prática.

No que tange ao atendimento dos alunos público-alvo da Educação Especial, nas Salas de Recursos Multifuncionais, o uso das tecnologias digitais pode ser considerado como um importante aliado no processo de ensino-aprendizagem.

Neste sentido, Silva (2017) destaca que para ocorrer a ampliação das oportunidades educativas dos estudantes que frequentam as SRM, elas devem estar bem equipadas, com recursos tecnológicos à disposição e sobretudo com profissionais que saibam manejar esses recursos.

Segundo Sá-Silva et al. (2021, p. 10):

As tecnologias digitais têm potencial para criar novas formas de atuar no contexto da educação especial/inclusiva e contribuir para o reconhecimento das diferenças à medida que apresenta uma variedade de recursos, que ampliam e podem favorecer as aprendizagens diante de diferentes especificidades e peculiaridades de estudantes PAEE.

Dessa forma, verifica-se que as SRM, apesar de já contar como espaço diferenciado, com práticas, recursos e materiais adaptados, ainda necessita de um trabalho de efetiva inclusão das tecnologias digitais na prática docente. Cabe destacar que a inclusão das TDIC na educação e no AEE, demanda de políticas públicas voltadas tanto para a inclusão social como para a inserção dessa população na sociedade digital.

Almeida $(2005$, p. 14$)$ aponta que "o exercício da cidadania no mundo atual implica no direito de utilizar todos os meios e tecnologias disponíveis para resolver problemáticas da própria vida, desenvolver a leitura e escrita sobre o ser humano, a sua história e realidade social". Tal questão se baseia principalmente pela falta de investimentos públicos, especialmente na formação continuada dos professores e na manutenção física exigida pela tecnologia.

Assim, o uso da tecnologia na educação, conforme consta nas diretrizes do Plano Nacional de Educação (BRASIL, 2014), para "a promoção humanística, científica, cultural e tecnológica do País" deve ser efetivado integralmente, mesmo considerando que após a efetivação da lei do PNE, no ano de 2017 (BRASIL, 2017), houve a instituição do "Programa de Inovação Educação Conectada", que tinha por objetivo apoiar a universalização do 
acesso à internet de alta velocidade e fomentar o uso pedagógico de tecnologias digitais na Educação Básica e também atuar sobre a formação de professores nesta área.

Todas estas questões são marcos que amparam a discussão sobre as atuais necessidades envolvidas no ambiente escolar, nas SRM, no uso da tecnologia e na formação continuada dos docentes.

\section{A FORMAÇÃO CONTINUADA DOCENTE PARA O USO DA TDIC}

Diante do contexto atual, onde é quase imperativo o uso das tecnologias digitais, os professores necessitam estar preparados para poder dinamizar, incluir e efetivamente utilizar os recursos disponíveis para o processo de ensino e aprendizagem.

Silva Neto et al. (2018) revelam que há um descompasso entre formação docente e inserção e uso das tecnologias no processo de ensino. Por isso, a formação continuada

é urgente, principalmente quanto às competências digitais necessárias para a atuação docente no atual contexto.

Em relação à formação continuada para os docentes, há a necessidade de preencher as lacunas que não foram trabalhadas durante a formação inicial, lacunas que podem ser ocasionadas por necessidades surgidas no decorrer das suas trajetórias na educação. Isso não se destina somente a uma formação tecnológica, há inúmeras outras necessidades a serem trabalhadas, porém, no viés da contemporaneidade, principalmente com a implementação do ensino remoto ocasionado pela pandemia gerada pelo COVID-19 no ano de 2020/2021, se identificou a urgência desta qualificação.

A problemática da integração das TDIC na educação precisa levar em conta a formação de professores em articulação com o trabalho pedagógico e com o currículo, não objetivando uma formação voltada para atuação no futuro, mas direcionada para o presente, tendo como pano de fundo a ação imediata do educador. (ALMEIDA; SILVA, 2011; ALMEIDA, 2005).

Neste sentido, Almeida (2003, p. 8) propõe a seguinte reflexão:

Sobre as práticas em realização e tenha chances de encontrar diferentes alternativas para avançar nesse trabalho de integração entre mídias e conhecimento, propiciando as interconexões entre aprendizagem e construção de conhecimento, cognição e contexto, bem como o redimensionamento do papel da escola como uma organização produtora de conhecimento.

Na mesma linha, sobre a formação de professores, Moran et al. (2000, p. 3) defende que:

Os cursos de formação continuada tenham como foco a construção do conhecimento e a interação; no equilíbrio entre o individual e o grupal, entre conteúdo e interação (aprendizagem cooperativa), um conteúdo em parte preparado e em parte construído ao longo do curso. 
Por meio da formação continuada, o professor se torna capaz de experienciar e explorar as tecnologias, o que resulta na possibilidade de relacionar e conectar as TDIC com as atividades pedagógicas, ao mesmo tempo em que pode discutir com o grupo em formação "sobre as possibilidades das atividades realizadas com aprendizes e buscar teorias que favoreçam a compreensão dessa nova prática pedagógica" (ALMEIDA; SILVA, 2011, p. 44).

Ainda sobre a formação para o uso da TDIC, Valente (2005, p. 32) destaca que:

Ao sentir-se mais familiarizado com as questões técnicas, o professor pode dedicarse à exploração da informática em atividades pedagógicas mais sofisticadas. Ele poderá integrar conteúdos disciplinares, desenvolver projetos utilizando os recursos das tecnologias digitais e saber desafiar os alunos para que, a partir do projeto que cada um desenvolve, seja possível atingir os objetivos pedagógicos que ele determinou em seu planejamento.

Em se tratando de formação de docentes em TDIC, a troca de experiências exitosas favorece o crescimento coletivo, estimulando o trabalho colaborativo na escola. É importante também a mudança de postura da equipe gestora da escola, a qual deve incentivar e investir na formação continuada dos educadores para que eles tenham "as condições necessárias para exercer o papel "facilitador" ou "mediador" de conhecimentos" integrando assim a tecnologia com as suas propostas pedagógicas" (CAMPOS, 2004, p 128).

Para que a formação de professores resulte na incorporação e integração das TDIC em sua prática pedagógica, aborda a necessidade de:

Uma interrelação entre as dimensões envolvidas no seu uso, onde a dimensão crítica humanizadora, deve ser ancorada em valores éticos e relacionar teoria e prática; a dimensão tecnológica, ao apropriar-se das técnicas favoreça a exploração e desenvolvimento de sua autonomia frente aos recursos; dimensão pedagógica, acompanhando e conhecendo o histórico do aprendizado do estudante e a dimensão didática, relacionada à sua prática pedagógica. (ALMEIDA, 2011, p. 6).

Corroborando com a necessidade do trabalho com as TDIC na formação continuada docente, assinala ainda que:

Trabalhar com as novas tecnologias não significa apenas preparar-se para um novo trabalho docente, mas para uma nova cultura que integra um processo de comunicação, de interação, interdependência e que amplia capacidade de as pessoas se conectarem com outras e, ao mesmo tempo, se constituírem e agirem como parte de um todo altamente habilitado e interdependente. (VIANA, 2004, p. 37).

Isso significa que professores que recebem durante a sua formação inicial, práticas pedagógicas relacionadas às TDIC no seu currículo, possuem maiores chances de aplicá-las em sua prática. 
Se a inserção das TDIC na formação dos professores já era uma exigência, com a pandemia e especificamente com o Parecer $n^{\circ} 5 / 2020$ do CNE orientou sobre o Ensino Remoto Emergencial - ERE, que segundo Hodges et al. (2020) não tem como intuito estruturar um ecossistema educacional robusto, mas ofertar acesso temporário aos conteúdos curriculares que seriam desenvolvidos presencialmente no ensino regular, determinando que:

As atividades pedagógicas não presenciais aplicam-se aos alunos de todos os níveis, etapas e modalidades educacionais. Portanto, é extensivo àqueles submetidos a regimes especiais de ensino, entre os quais os que apresentam altas habilidades/ superdotação, deficiência e Transtorno do Espectro Autista (TEA), atendidos pela modalidade de Educação Especial. (BRASIL, 2020, p.14).

Dessa forma, as atividades de mediação pedagógicas entre os professores e os alunos das SRM, com base nas relações e trocas estabelecidas no ambiente social mediatizado pela cultura foram agravadas durante a pandemia. (VIGOTSKY, 1997).

\section{PROCEDIMENTOS METODOLÓGICOS}

Este estudo foi realizado tendo como base a pesquisa de natureza qualitativa, utilizando como instrumento de coleta de dados um formulário do Google Forms e desenvolvendo uma análise pautada na pesquisa exploratória que, segundo GIL (1999, p. 41), é uma pesquisa que propicia "maior familiaridade com o problema, com vistas a tornálo mais explícito ou a construir hipóteses".

Em um primeiro momento, foi realizado um levantamento bibliográfico em periódicos nacionais que pudessem subsidiar as reflexões sobre a temática. Em seguida, foi elaborado um questionário, por meio do Google Forms, a fim de conhecer a realidade dos professores que estavam atuando nas SRM durante a pandemia com as TDIC.

O formulário foi enviado apenas para duas regiões do estado, a capital e um município da região noroeste, local de residência e atuação das pesquisadoras. Essa delimitação ocorreu em virtude da própria pandemia, da imposição de distanciamento social e da dificuldade de encontrar professores. Dezessete professores responderam e retornaram o questionário, eles atuam na SRM da rede pública estadual do Paraná, sendo oito da capital e nove de um município do interior do estado.

O questionário teve como objetivo investigar como se deu a inclusão das TDIC nas SRM durante o período de pandemia e identificar possíveis lacunas na formação continuada dos professores quanto ao uso das tecnologias. O questionário criado foi do tipo misto, com treze questões fechadas e abertas, sendo sete abertas e seis fechadas. O formulário do Google Forms ficou disponível para respostas por um período de trinta 
dias. Cabe destacar que os professores sujeitos da pesquisa concordaram em participar da pesquisa por meio de um termo de consentimento enviado junto com o formulário.

\section{APRESENTAÇÃO E ANÁLISE DOS RESULTADOS}

Para a apresentação e análise dos dados, foram elencados metodologicamente alguns eixos relacionados à proposta da pesquisa e aos objetivos pretendidos: perfil dos professores; o uso das TDIC nas sem e a formação docente para o uso das TDIC.

\subsection{Perfil dos professores}

A construção do perfil dos respondentes é importante para identificar o grau de familiaridade dos docentes com as TDIC e o tempo de experiência nas SRM. Em relação à faixa etária, o Gráfico 1 aponta que $70,59 \%$ dos sujeitos se encontram na faixa dos 36 aos 50 anos. Apenas um professor, ou 5,88\% pode ser considerado ainda iniciante, tendo em vista sua faixa etária dos 18 aos 35 anos. Quatro professores, ou 23,53\%, já devem estar no final de carreira por estarem na faixa dos 51 aos 70 anos de idade.

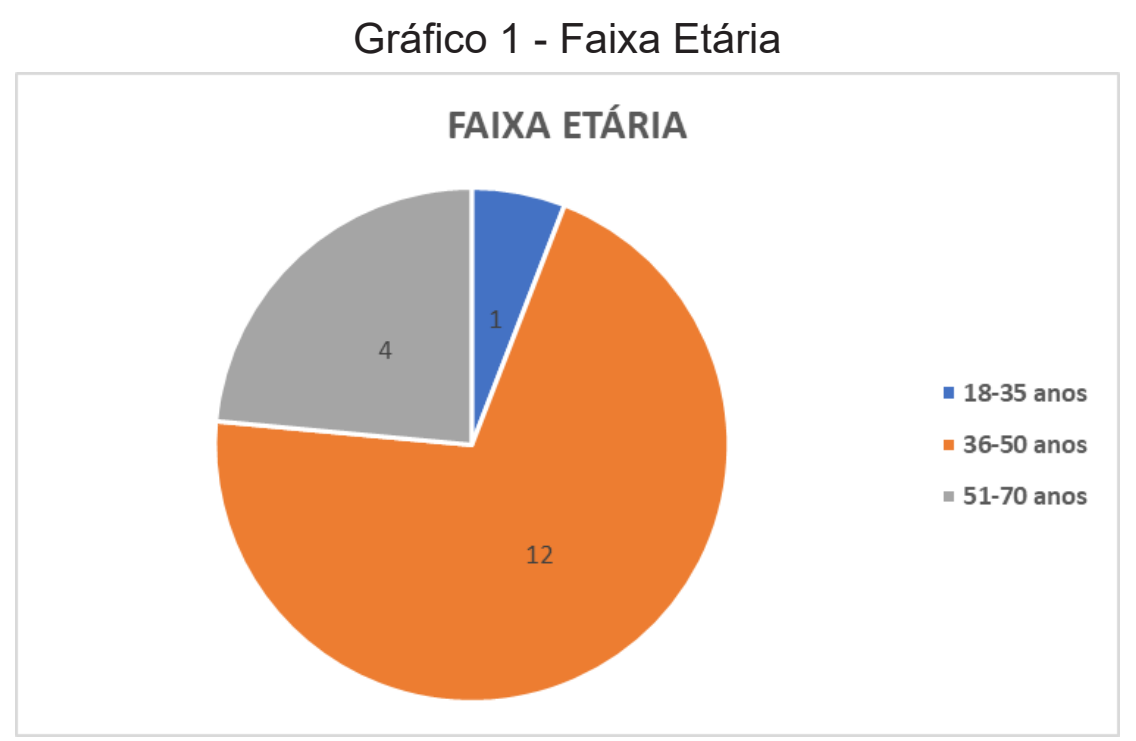

Fonte: Elaborado pelas autoras (2020).

No que tange à experiência dos professores na Educação Básica e nas SRM, o Gráfico 2 demonstra que nove, ou 52,9\%, dos professores são experientes na docência, no entanto apenas seis, ou 35,3\%, desses atuam na SRM. Outro dado interessante identificado foi que a atuação nas salas de recursos multifuncionais é uma realidade de 1 a 5 anos de atuação para dez, ou 58,8\%, dos respondentes da pesquisa. 
Gráfico 2 - Experiência de docência

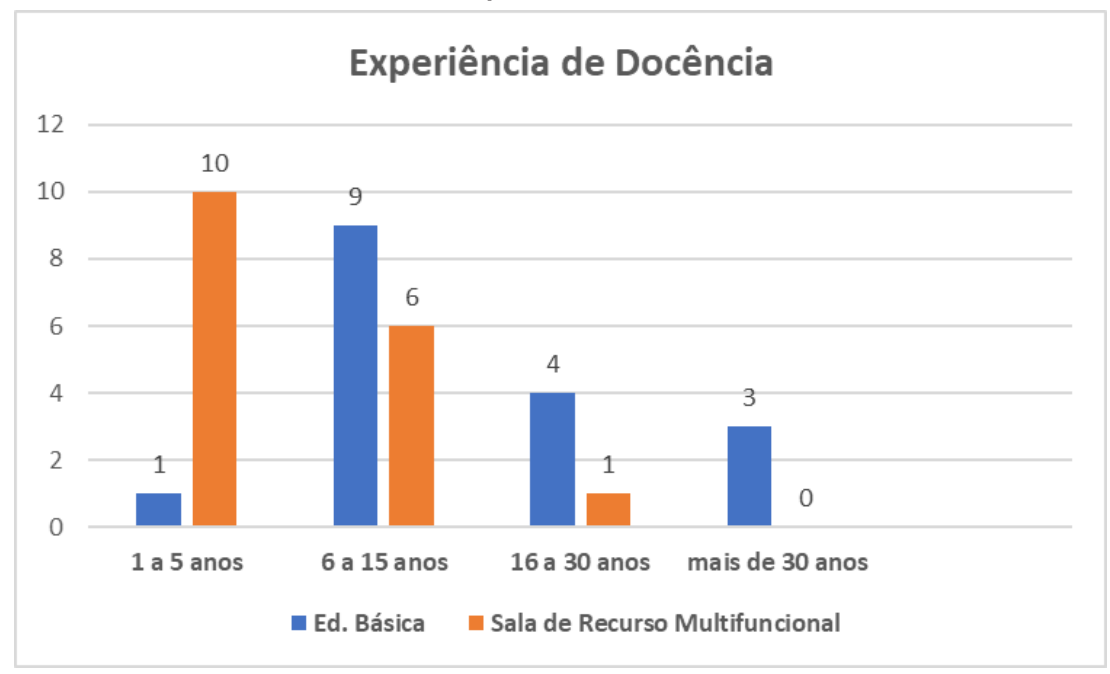

Fonte: Elaborado pelas autoras (2020).

Observando os dados e se pautando em estudos como os de Miranda (2016), que enfatiza que as professoras das SRM apontam a complexidade de sua atuação, pois precisam atender diferentes tipos de deficiência, o trabalho nas SRM deve ser diversificado e ao mesmo tempo individualizado, ocasionando um sentimento de despreparo para a função, reduzindo a procura para docência nas SRM ou delegando essa função para os professores mais jovens.

\subsection{0 uso das TDIC nas SRM}

Outro aspecto abordado foi o uso das TDIC nas SRM antes da pandemia pelo Coronavírus. As respostas demonstram que dez, ou $68,8 \%$, dos professores responderam que já utilizavam recursos tecnológicos e ferramentas digitais em seus atendimentos e apenas seis, ou $31,3 \%$, dos professores afirmaram que não utilizavam as TDIC e um respondente deixou em branco a resposta.

Apesar dos professores de SRM pontuarem que já utilizavam as TIDC durante os atendimentos, ficou evidente que o seu uso não se caracterizava como instrumento essencial no dia a dia em sala de aula, pois estava relacionada ao que Masetto (2000) chamava de tecnologias assentadas em estratégias convencionais, ou ainda na própria concepção do trabalho pedagógico a ser desenvolvido nas SRM, ou seja, identificar, elaborar, produzir e organizar serviços, recursos pedagógicos de acessibilidade e procedimentos de acordo com as necessidades específicas dos educandos e ensinar e usar a tecnologia assistiva para a ampliação de habilidades, promovendo a autonomia e a participação do educando (BRASIL, 2009).

Ao serem questionados se começaram a utilizar as TDIC devido à situação imposta pela pandemia, nove, ou $56,3 \%$, dos professores afirmaram que sim, enquanto 
sete, ou 43,8\%, dos professores responderam que não foi a pandemia que os levou a utilizar as TDIC. No entanto, há de se considerar que 31,3\% já haviam respondido que não utilizavam as TDIC antes da pandemia, de fato, apenas dois, ou 12,5\%, dos professores realmente começaram a utilizar as TDIC motivados por outras causas que não a pandemia. Cabe mencionar que um professor deixou a pergunta sem resposta.

Esses dados evidenciam que os professores utilizavam recursos diferenciados, mas com a implantação do ensino remoto foram obrigados a rever suas práticas e até mesmo a concepção de tecnologias que possuíam. A pandemia exigiu novas formas de ensinar, de estar presente, em contato virtual com seus alunos, e por isso uma nova gama de recursos tiveram que ser inseridos na prática docente.

Conforme destacam Loureiro, Rodrigues e Mattar (2020, p. 2), os professores reinventaram:

\begin{abstract}
Estratégias e definiram novas dinâmicas, adequando-se às necessidades dos alunos, às contingências, às restrições e às potencialidades tecnológicas, adaptando-se pouco a pouco ao novo normal apoiado e mediado pelas tecnologias digitais.
\end{abstract}

Sobre os recursos mais utilizados nas SRM durante o período da pandemia, os respondentes indicaram: celulares e computadores e as ferramentas do google como classroom, meet, formulário. Também foram citados jogos online, vídeos explicativos, WhatsApp e chamadas de vídeo. Sobre as vantagens do uso das TDIC nas salas de recursos multifuncionais, as respostas foram favoráveis à sua implantação, pois consideram que os recursos tecnológicos aumentam o interesse dos estudantes, sendo mais atraentes, esses recursos facilitam a interação e ampliam as possibilidades de aprendizagem, conforme relatos:

"É possível desenvolver vários jogos e atividades que atraem os alunos". (Participante 2).

"Os alunos gostam, esse fator é primordial na minha opinião. Atrai a criança e ela aprende brincando". (Participante 5).

"Acesso rápido sem a utilização de impressão de papéis é mais atraente e motivador para o aprendente." (Participante 11).

"Interesse dos estudantes, oferecem diferentes conteúdos de forma mais atrativa (vídeos, textos), contato e trocas com outras pessoas a distância". (Participante 12). "Facilita a interação dos alunos nas aulas e eles podem se tornar os protagonistas da própria aprendizagem, não somente meros ouvintes". (Participante 14).

Dessa forma, as respostas corroboram com as ideias de Valente (2005) que considera que as TDIC são úteis para a realização de tarefas, como resolver problemas ou desenvolver projetos, possibilitando que o aprendiz seja um autor ativo e não mais um passivo receptor da informação. Especificamente para a Educação Inclusiva, segundo Viana, Vasconcelos e Silva (2018, p. 13), as TDIC demandam novas formas de atuar neste 
contexto, contribuindo "para o reconhecimento das diferenças a medida em que proporciona diversificados recursos, para atender as diferentes especificidades e peculiaridades de estudantes com deficiência".

\subsection{A formação docente para o uso das TDIC}

Com relação à formação para o uso das TDIC, acentuadas com o início do ensino remoto emergencial, apenas seis, ou (35,2\%), dos professores afirmaram que receberam formação continuada da mantenedora para o uso das TDIC. Observou-se que os professores que afirmaram ter recebido formação são os que atuam no município do interior do Estado. Dos professores da rede estadual que atuam na capital do Estado, nenhum mencionou que recebeu formação continuada quanto ao uso de ferramentas para o período da pandemia, buscando de forma individualizada aprender e pesquisar sobre os recursos indicados pela rede.

Outro aspecto destacado pelos professores foi a falta de tempo para preparação para o uso das TDIC, o que Valente (2005) considera importante na formação em TDIC. No entanto, nos relatos, os professores destacam que foram aprendendo conforme era necessário à sua utilização imediata. Este despreparo em relação ao manejo das tecnologias digitais de informação e comunicação, impacta negativamente na produtividade do trabalho dos professores e alunos, além de despertar variados efeitos colaterais em sua saúde.

A necessidade praticamente imediata da utilização das TDIC como possibilidade da manutenção das aulas, ainda que de forma remota, acabou desfavorecendo uma parcela dos estudantes sem acesso à internet e recursos digitais. Esses alunos precisaram acompanhar pela televisão as aulas assíncronas genéricas e recorrer a materiais impressos entregues quinzenalmente pela escola, comprometendo ainda mais a qualidade do seu aprendizado.

Neste contexto, foi imprescindível pensar em outras formas de promover o atendimento aos alunos de maneiras não presenciais, utilizando-se de momentos síncronos e assíncronos para o trabalho com os conteúdos e a interação entre professores e alunos. Porém, essa estratégia adotada para a implementação do ensino remoto emergencial de forma rápida, acabou gerando a "virtualização" do ensino tradicional, modificando apenas o ambiente de sala de aula para a casa dos estudantes, mantendo aulas expositivas onde o professor ainda ocupa a posição de protagonista principal, detentor e transmissor da informação, ou seja, nada comparado com uma proposta efetiva de utilização das TDIC a partir de uma formação coerente e bem fundamentada, que possibilite aos docentes apropriar-se do domínio das tecnologias da educação para que seja capaz de construir formas alternativas de acesso ao conhecimento por estudantes com deficiência (CORTELAZZO, 2012). Ou seja, a implementação das TDIC na educação vai muito além do prover acesso 
à informação. Elas devem estar inseridas e integradas aos processos educacionais, agregando valor à atividade que o aluno ou o professor realiza, como acontece com a integração das TDIC em outras áreas. (VALENTE, 2005, p. 162).

Em relação ao questionamento sobre a aprendizagem dos estudantes da SRM utilizando as TDIC durante a pandemia, os professores relataram dificuldades para contatar os estudantes inicialmente, dificuldades para conseguir acesso aos equipamentos tecnológicos, dificuldades para que eles compreendessem o funcionamento das ferramentas disponíveis para as aulas remotas, a distância provocada pelo isolamento social, a falta de conhecimento, tanto de estudantes como dos familiares para auxiliá-los, problemas que prejudicaram o acesso às aulas, conforme ilustram os depoimentos a seguir:

"A maioria dos alunos tiveram bastantes dificuldades com a internet e com o uso das tecnologias, pois não tiveram uma formação para o uso". (Participante 1)

"A falta do contato dificulta muito, as atividades, jogos, interação, que são essenciais para a vida e aprendizado. Alunos com maior suporte e diversidades de atividades apresentam melhor desenvolvimento". (Participante 4).

"Ruim, sem o atendimento presencial, muitos alunos não conseguem dar continuidade na sua aprendizagem significativa". (Participante 7).

"Após uma longa fase de adaptação ao sistema de ensino a distância, o qual mudou totalmente a rotina dos alunos, eles passaram a responder às novas formas de aprendizagem sem muitas dificuldades." (Participante 13).

A aprendizagem, apesar do destaque para os esforços dos professores, foi considerada pelos sujeitos da pesquisa como insatisfatória, prejudicada especialmente pela distância, justificada pela necessidade comum dos estudantes PAEE de recursos materiais concretos para a compreensão das atividades propostas em sala de recursos multifuncionais, ou seja, o processo de adaptação foi inadequado devido à urgência do momento, prejudicando principalmente os estudantes com dificuldades de aprendizagem e pela falta de formação docente na temática.

Moran (2015, p. 30) considera fundamental "capacitar coordenadores, professores e alunos para trabalhar mais com metodologias ativas, com currículos mais flexíveis, com inversão de processos" e que isso pode ser iniciado com mudanças pontuais para posteriormente obter-se mudanças profundas em suas práticas metodológicas.

Não é uma mudança rápida e nem sempre fácil, a formação dos docentes deve prever a utilização das TDIC como componente curricular para que eles tenham condições de adaptar-se à medida que as adversidades ocorrerem, conforme destaca Moran (2015, p.31):

Todos os processos de organizar o currículo, as metodologias, os tempos, os espaços precisam ser revistos e isso é complexo, necessário e um pouco assustador, porque não temos modelos prévios bem-sucedidos para aprender. Estamos sendo pressionados para mudar sem muito tempo para testar. 
Assim, é fundamental e urgente a reorganização do universo escolar, desde a postura dos professores e suas práticas, até a escolha sobre como incluir as TDIC nesse novo cotidiano, respeitando condições materiais, locais, perfil dos alunos e dos docentes, entre outras questões.

Para finalizar, os professores foram questionados sobre quais ações consideram ser essenciais a fim de melhorar a prática pedagógica com o uso das TDIC nas salas SRM e obtivemos as seguintes respostas: a formação inicial e continuada que foi pontuada por todos os respondentes, a necessidade de investimento em tecnologias digitais, o incentivo ao uso de recursos materiais apropriados pela escola e maior tempo para planejamento de propostas e elaboração de novas práticas. Os dados coletados confirmam a premissa de que as TDIC precisam fazer parte da rotina das SRM, integrando-se a um planejamento pedagógico efetivo de modo a possibilitar que alunos com deficiência possam reconstruir seus conhecimentos por meio de formação continuada adequada e efetiva aos docentes.

\section{CONSIDERAÇÕES FINAIS}

Os dados levantados no estudo nos permitem considerar que as SRM são locais complementares, incentivadores e determinantes para o desenvolvimento acadêmico e social dos alunos público-alvo da Educação Especial. Nestes espaços, os professores utilizam de dinâmicas e recursos diferenciados, em contraste com as salas regulares, para desenvolver as habilidades e intervir nas dificuldades dos seus alunos. Por isso, a grande maioria dos professores já usavam as TDIC durante suas aulas, antes da pandemia: jogos online, mesa alfabeto e games em geral, porém, a intervenção presencial era e continua sendo fator essencial para estimular o desenvolvimento do estudante, incluindo o uso da tecnologia.

Sobre o ensino durante o período de pandemia, é importante destacar alguns aspectos levantados pelos entrevistados em relação àqueles que acabaram prejudicando os estudantes: a falta dos atendimentos presenciais, dificuldades no manuseio das tecnologias nas aulas remotas e a carência de equipamentos (celulares e computadores). A ausência dessa "aproximação" gerou, em muitos casos, retrocessos e dificuldades tanto acadêmicas quanto sociais.

Apesar dos problemas encontrados no ensino remoto emergencial, os professores foram unânimes em reconhecer a importância do uso das TDIC na educação, principalmente na SRM, pois quando bem exploradas, com segurança, habilidade e boa infraestrutura, tornam as aulas mais atrativas e permitem um melhor desenvolvimento das habilidades dos estudantes. Sendo ainda a única alternativa para a continuidade do processo de ensino e aprendizagem dos alunos durante o período de isolamento social ocasionado pela pandemia. 
Quanto à questão levantada neste trabalho: os professores receberam formação continuada suficiente para inserir as TDIC nas SRM durante a pandemia? Podese inferir, pelos dados coletados, que durante a pandemia o trabalho maior recaiu sobre o professor, aumentando suas dificuldades, pois, se o trabalho nas SRM antes da pandemia já demandava uma formação continuada para o atendimento do aluno com deficiência, situação que foi agravada com o ensino remoto emergencial, os professores necessitaram fazer uso ainda maior de tecnologias que na maioria das vezes não conheciam. O que suscita a ideia de que se os profissionais da educação tivessem recebido uma formação ou mantido contato com as TDIC anteriormente, os problemas que surgiram seriam amenizados mais rapidamente.

Enfim, é essencial sinalizar a necessidade de políticas e de investimentos públicos na educação para uma formação continuada de qualidade para os professores, bem como a manutenção das escolas brasileiras, no que tange ao aparato tecnológico para que a Educação Inclusiva possa ser realmente favorecida. Pode-se inferir ainda que o trabalho pós-pandemia carece de maior atenção tanto no atendimento dos alunos das SRM como da formação continuada do professor.

\section{REFERÊNCIAS}

ALMEIDA, Maria Elizabeth B. de. Prática e Formação de Professores na Integração de Mídias, Série "Pedagogia de Projetos e Integração de Mídias". Programa Salto para o Futuro, set., 2003. Disponível em: http://www.tvebrasil.com.br/salto-Boletim 2003. Acesso em: 13 jan. 2021.

ALMEIDA, Maria Elizabeth B. de. Tecnologias na educação, formação de educadores e recursividade entre teoria e prática: trajetória do programa de pós-graduação em educação e currículo. Revista E-Curriculum, São Paulo, v. 1, n.1, dez-jul. 2005. Disponível em: https://revistas.pucsp.br/index.php/curriculum/article/ viewFile/3165/2095. Acesso em: 15 fev. 2021.

ALMEIDA, Maria Elizabeth B. de; SILVA, Maria da Graça Moreira da. Currículo, Tecnologia e Cultura Digital: espaços e tempos de web currículo. Revista E-Currículum, São Paulo, v. 7, n.1, abr., 2011. Disponível em: https://revistas.

pucsp.br/index.php/curriculum/article/viewFile/5676/4002. Acesso em: 8 jan. 2021.

BRASIL. Lei no 13.005, de 25 de junho de 2014. Aprova o Plano Nacional de Educação - PNE e dá outras providencias. Diário Oficial da União, Brasília, DF, 26 jun. 2014, Disponível em: http://www.planalto.gov.br/ccivil_03/_Ato20152018/2017/

Decreto/D9204.htm. Acesso em: 9 jan. 2021.

BRASIL. Conselho Nacional de Educação. Câmara de Educação Básica. Resolução $\mathrm{n}^{\circ} 4$, de 2 de outubro de 2009. Institui as Diretrizes Operacionais para o Atendimento Educacional Especializado na Educação Básica, na modalidade Educação Especial. 
Diário Oficial da União, Brasília, DF, 5 out. 2009. Disponível em: http://portal.mec. gov.br/index.php?option=com_content\&view=article\&id=16761\&ltemid=1 123. Acesso em: 19 jan. 2021.

BRASIL. Portaria normativa $n^{\circ} 13$, de 24 de abril de 2007 . Dispõe sobre a criação do Programa de Implantação de Salas de Recursos Multifuncionais. Diário Oficial da União. Brasília, DF, 26 abr. 2007. Disponível em: http://portal.mec.gov.br/index.php? option=com_docman\&view=download\&alias=9935-portaria-13-24-abril 2007\&ltemid =30192. Acesso em: 19 jan. 2021.

BRASIL. Conselho Pleno. Conselho Nacional de Educação. Parecer $n^{\circ}$ 5, de 28 de abril de 2020. Reorganização do Calendário Escolar e da possibilidade de cômputo de atividades não presenciais para fins de cumprimento da carga horária mínima anual, em razão da Pandemia da COVID-19. Diário Oficial da União. Brasília, DF, 1 jun. 2020. Disponível em: https://normativasconselhos.mec.gov.br/normativa/pdf/

CNE_PAR_CNECPN52020.pdf. Acesso em: 19 jan. 2021.

BRASIL. Decreto $n^{\circ}$ 9.204, de 23 de novembro de 2017. Institui o Programa de Inovação Educação Conectada e dá outras providências. Diário Oficial da União. Brasília. D.F. 24 de novembro de 2017. Disponível em: http://www.planalto.gov.br/ ccivil_03/_Ato2015-2018/2017/Decreto/D9204.htm. Acesso em: 19 jan. 2021.

CABRAL, Mozanilde Santos Nunes; BOTTENTUIT JUNIOR, João Batista. Práticas de Ensino e Uso das Tecnologias no Atendimento Educacional Especializado: enfoque nas salas de recursos multifuncionais. Renote - Novas Tecnologias na Educação, Porto Alegre, v. 14, n. 1, p. 1-10, jul., 2016. Disponível em: https://www.seer.ufrgs.br/renote/ article/view/67356. Acesso em: 19 jan. 2021.

CAMPOS, Maria M. A. A incorporação da informática educativa nas escolas públicas de ensino médio de Maceió. In: MERCADO, L. P. L (org). Tendências na utilização das tecnologias da informação e comunicação na educação. Maceió: EDUFAL, 2004.

CORTELAZZO, lolanda Bueno de Camargo. Formação de professores para uma educação inclusiva mediada pelas tecnologias. In: GIROTO, C. R. M; POKER, R. B; OMOTE, S. (org.). As tecnologias nas práticas pedagógicas inclusivas. Marília: Oficina Universitária; São Paulo: Cultura Acadêmica, 2012.

GIL, A. C. Métodos e técnicas de pesquisa social. 5. ed. São Paulo: Atlas, 1999. HODGES, C. et al. The Difference Between Emergency Remote Teaching and Online Learning. EDUCAUSE Review, 2020. Disponível em: https://er.educause. edu/articles/2020/3/the-differencebetween-emergency-remote-teaching-and-onlinelearning\#fn3. Acesso em: 19 jan. 2021.

LOUREIRO, Ana; RODRIGUES, Elsa da Piedade; MATTAR, João. Educação online em tempos de pandemia: desafios e oportunidades para uma escola inclusiva. Revista Interações. São Paulo, n. 54, p.1-7, 2020. Disponível em: https://revistas. rcaap.pt/interaccoes. Acesso em: 19 jan. 2021. 
MARTINIAK, Vera Lúcia; FOLTRAN, Elenice Parise; OLIVEIRA, Rita de C. Da Silva. Formação de professores no contexto atual: desafios e limites da tecnologia no processo educativo. In: ROCHA, Simone Albuquerque da; WILLMS, Elni Elisa. Formação de professores: entre a esperança e a pandemia. São Paulo: Edições Verona. 2020.

MASETTO, Marcos T. Mediações pedagógicas e o uso das tecnologias. In: MORAN. José M.; MASETTO, Marcos T.; BEHRENS Marilda A. Novas tecnologias e mediações pedagógicas. Campinas, SP: Papirus. 2000.

MORAN, José Manuel. Ensino e aprendizagem inovadores com tecnologias audiovisuais e telemáticas. In: MORAN, José Manuel; MASETTO, Marcos T.; BEHRENS, Marilda A. Novas tecnologias e mediação pedagógica. Campinas: Papirus, 2000. Disponível em: http://www.eca.usp.br/prof/moran/site/textos/ tecnologias_eduacacao/integracao.pdf. Acesso em: 18 jan. 2021

MORAN, José Manuel. Mudando a educação com metodologias ativas. In: SOUZA, Carlos Alberto de; MORALES, Ofelia Elisa Torres (orgs). Convergências Midiáticas, Educação e Cidadania: aproximações jovens. Paraná: UEPG, 2015. Disponível em: http://www2.eca.usp.br/moran/wp-content/uploads/2013/12/ mudando_moran.pdf. Acesso em: 19 jan. 2021.

PRENSKY, Marc. Digital Natives, Digital Immigrants. NCB University Press, v. 9, n. 5, out., 2011. Disponível em: http://www.marcprensky.com/writing. Acesso em: 19 jan. 2021.

SÁ-SILVA, Jackson Ronie; FERREIRA, Ana Paula Almeida; SILVA, Jarlisse Nina Beserra; PADILHA, Maritania dos Santos. O atendimento educacional especializado e a utilização das tecnologias digitais nas salas de recursos multifuncionais. Cadernos do Aplicação. Porto Alegre. v. 34, n. 2, jul./dez., 2021. Disponível em: https://seer.ufrgs.br/ CadernosdoAplicacao. Acesso em: 19 jan. 2021.

SILVA, Rose Madalena Pereira da. Atendimento Educacional Especializado e as tecnologias contribuindo para a aprendizagem dos surdos. Diversitas Journal. São Paulo, v. 2. n. 2, mai./ago., 2017. Acesso em: 19 jan. 2021.

SILVA NETO, Antenor de oliveira; ÁVILA, Everton Gonçalves; SALES, Tamara Regina Reis; AMORIN, Simone Silveira; NUNES, Andrea Karla; SANTOS, Vera Maria. Educação Inclusiva: uma escola para todos. Revista Educação Especial. São Paulo, v. 31, n. 60, jan./mar., 2018. Disponível em: https://periodicos.ufsm.br /educacaoespecial/article/view/24091/pdf. Acesso em 19 jan. 2021.

VALENTE. J. A. Pesquisa, comunicação e aprendizagem com o computador: o papel do computador no processo de ensino-aprendizagem. In: ALMEIDA, Maria Elizabeth B. de; MORAN, José Manuel (orgs). Integração das Tecnologias na Educação. Brasília: Secretaria de Educação a Distância, 2005. Disponível em: https://pt.slideshare.net/volneif/ integrao-das-tecnologias-na-educao-44138763. Acesso em: 15 jan. 2021. 
VIANA, Maria Aparecida Pereira. A internet na educação: novas formas de aprender, necessidades, e competências no fazer pedagógico. In: MERCADO, Luís Paulo Leopoldo (org.). Tendência na utilização das tecnologias da informação e comunicação na educação. Maceió: UFAL, 2004. Disponível em: http://www.repositorio.ufal.br/bitstream/ riufal/1349/1/Tendências\%20na\%20utilização\%20das \%20tecnologias $\% 20$ da\%20 informação\%20e\%20comunicação\%20na\%20educação.pdf. Acesso em: 19 jan. 2021.

VIANA, Flávia Roldan; VASCONCELOS, Jásia Sara de Lima; SILVA, Layse Kelly Santos da. Práticas Inclusivas digitais no contexto do atendimento educacional especializado: interfaces possíveis. Prometeu, Rio Grande do Norte, Ano IV, n. 4, p. 1-17, 2018. Disponível em: http://lte.ce.ufrn.br/prometeu/edicoes/edicao_2018.html. Acesso em: 19 jan. 2021.

VYGOTSKY. L. S. Obras escogidas V. Madrid: Centro de Publicaciones Del MEC y Visor Distribuciones, 1997.

Recebido em 19 de outubro de 2021 Aprovado em 11 de novembro de 2021 